\section{Immediate memory for simultaneously presented items: The effects of search for a target item*}

\author{
PETER L. DERKS + and JAMES GOALDER \\ College of William and Mary, Williamsburg, Va, 23185 \\ and \\ LYNN S SCHULZ \\ University of Delaware, Newark, Del. 19711
}

Arrays of eight consonants were presented for $0.5,1,2$, or 4 sec, and Ss searched for a specific target consonant in each array. The search task reduced probed recall of the other items in the array. This decrease was greatest when the target was not present or was in the middle of the array. Consonants on the end of the array furthest from the target showed greater improvement in recall with longer exposures than did items closer to the target. Thus, the target item served as a high-priority event and detracted from the recall of the array as a whole and adjacent items in particular.

When an item in an array or a list is isolated from the other items, the recall pattern of the list favors the retention of that item (Harcum, 1967; von Restorff, 1933). The effect of this isolation of the recall of adjacent items, however, depends on the nature of the isolation (Wallace, 1965). In the present experiment, single items in an array were isolated as the target of a search task. This technique was designed to produce maximal isolation of target items without perceptual additions and without changes in the type of materials employed. The question was, does the search process facilitate, interfere with, or perhaps differentially affect encoding and retrieval of target and adjacent nontarget items? In other words, does the target of a search task serve as an anchor point to aid recall (Feigenbaum \& Simon, 1962) or as a high-priority event to reduce effective presentation time of other items (Schulz, 1971; Tulving, 1969). Recall for target and nontarget items was assessed by a poststimulus probe procedure. By varying the presentation time, the amount and kind of information encoded could be assessed, as well as inferences made about the interaction between search and memory.

$$
\text { SUBJECTS }
$$

Forty undergraduate students at the College of William and Mary were

* This research was supported in part by U.S. Public Health Service Grant $\mathrm{MH} 08889$ from the National Institute of Mental Health. The participation of Anne Larson in the conduction of pilot studies and the aid of Linda Jones with the analysis of the present experiment are gratefully acknowledged.

tRequests for reprints and further information should be sent to Peter L. Derks. Dept. of Psychology, College of William and Mary. Williamsburg, Va. 23185. assigned randomly to the four exposure durations investigated, 10 to each duration. They were guaranteed $\$ 1$ for their participation and received 1c for each correct response, not including a practice session. No $\mathrm{S}$ earned less than $\$ 1$ per session, with a maximum possible payoff of $\$ 4.80$ for the entire experiment. Depending on exposure time, either one or two sessions of approximately $1 \mathrm{~h}$ were needed to complete the experiment. The Ss that served in two sessions showed no consistent differences between sessions.

MATERIALS AND PROCEDURE

Horizontal arrays of eight

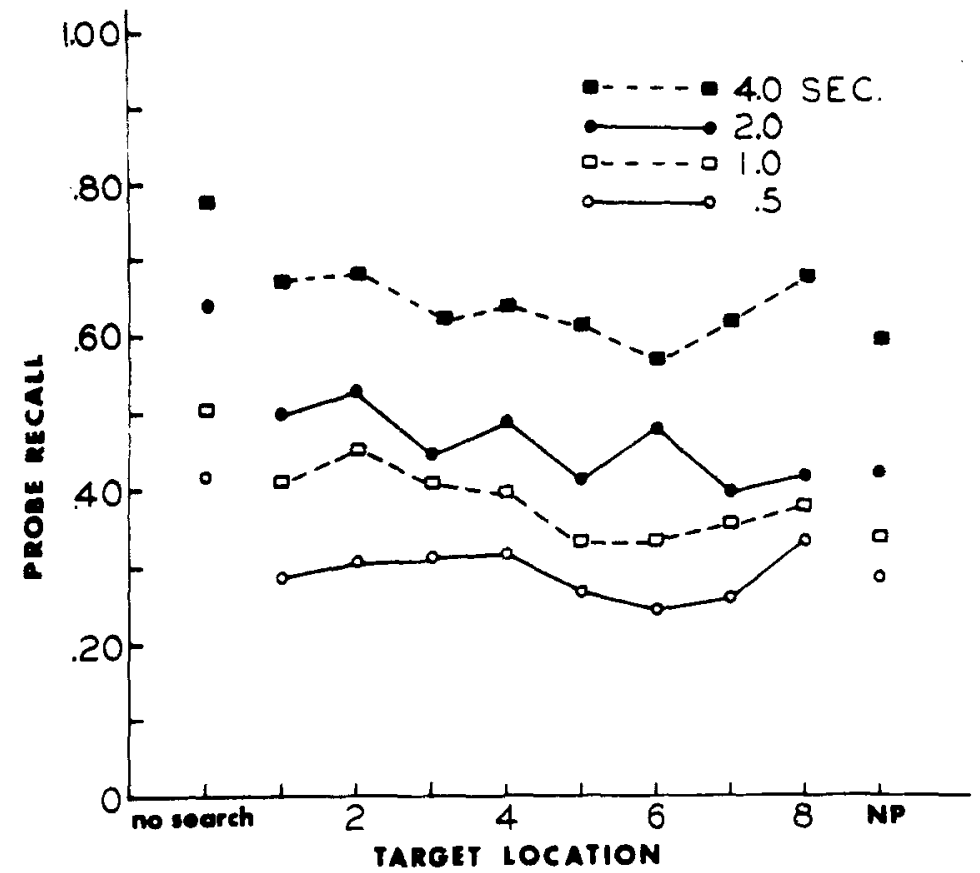

Fig. 1. Proportion of probed items recalled in the correct position as a function of target location and exposure time. consonants were presented for $0.5,1$, 2 , or $4 \mathrm{sec}$ by a Lafayette 2303A memory drum. The arrays were composed of pica capital letters typed with no spaces between them. The consonants were selected randomly without repetition within arrays, and a different array was presented on each trial.

The Ss were instructed that a single consonant would appear on the memory drum prior to presentation of the stimulus array. Their task was to search for this target in the array so as to be able to indicate its presence or absence as well as its location in the array. The consonants given as targets actually occurred in the arrays on $80 \%$ of the trials and occurred equally often in each of the eight positions. The targets were not present (NP) in the array on $20 \%$ of the presentations.

The Ss were further instructed that a consonant would also appear immediately following exposure of the array. The $\mathbf{S}$ was required to recall whether that consonant had been present in the array and, if so, to indicate $i t s$ location. The consonants given as recall probes were actually in the array on $80 \%$ of the trials, equally often in each position, and were NP on $20 \%$ of the trials.

The target consonant was presented in a location that corresponded with the first letter in the array, and the probe consonant followed the array in a location that corresponded with the eighth (last) letter in the array. In the memory drum, target and probe exposure times were necessarily the 


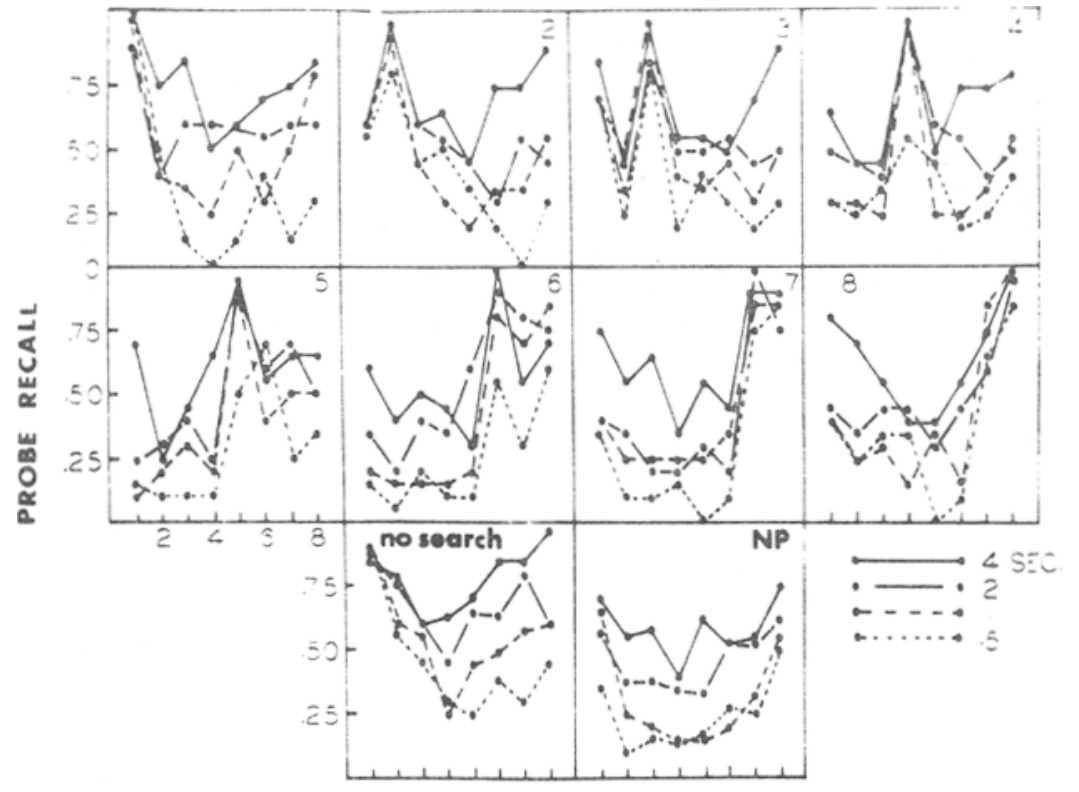

PROBE LOCATION

Fig. 2. Recall as a function of the location in the array of the probed item and exposure time. Each box is for the target position or condition indicated.

same as the duration of the array. The step time was $0.3 \mathrm{sec}$ from stop to stop; therefore, the stimulus array was in motion for $0.3 \mathrm{sec}$ of each exposure time. The targets, arrays, and probes, however, were not simultaneously visible.

Each $S$ recorded the target and probe consonants in location on response sheets with rows of eight numbered locations and a column for NP. The $\mathrm{S}$ could begin to respond as soon as the probe appeared, and $S$ was given as much time as was needed to complete the response. The intertrial interval, therefore, was unspecified but brief. If target and probe were the same, Ss were to record and circle the consonant. The Ss were not asked to recall items from the arrays other than the targets and probes. There was no immediate feedback about accuracy.

Forty practice trials with combined target and probe consonants were given prior to beginning the experiment and were not scored. All possible combinations of target and probe locations were then tested twice, for a total of 200 combination trials for each S.

Performance on the search task without the recall task was also evaluated for 40 trials, 4 for each position in the array and 8 for NP. Pilot data indicated that search perl rmance alone was perfect for exposures longer than $1 \mathrm{sec}$; therefore, search without recall was not tested for the 2- and 4-sec groups. Performance on the recall task without the search task (no search) was similarly tested for 40 trials, with the probe appearing 4 times in each position in the array and being NP on 8 trials. All exposure duration groups were tested on the no-search task.

The search without recall and no-search conditions were included as units half to three-quarters of the way through the 200 combination trials. Order of presentation was randomized by blocks of 10 arrays for search without recall and no-search conditions, and by blocks of 12.13 arrays for the combined search and recall condition. Target and probe positions did not repeat more than twice per block.

\section{RESULTS}

The effect of the location of the target and exposure time on probe recall is shown in Fig. 1. Increased exposure time significantly improved recall of the probed item $[F(3,36)=19.53, \quad p<.001]$. Within search conditions, the location of the target item had a small but significant effect on probe recall $[F(8,288)=$ $3.54, p<.001]$. When the target was NP, however, probe recall was not significantly different from the presentation of the target in Positions $4,5,6$, and 7 . (The Scheffé allowance for $p=.05$ is a difference of .023.) The interaction with exposure time was not significant $[\mathrm{F}(24,288)=$ 0.94 ].

All locations of the target resulted in search that decreased probe recall relative to no search, even if the target item was in the initial location. Averaging over probe locations, performance on 4 sec with search was about equal to 2 sec with no search (.635 to .642 correct probe recall), 2 sec with search was less than 1 sec with no search (.458 to .505 correct probe recall), and $1 \mathrm{sec}$ with search was about equal to $.05 \mathrm{sec}$ with no seareh (.404 to .420 correct probe recall). The search task reduced effective presentation time by about half.

To compare the search and no search conditions, analyses of variance were applied to omission, commission, and location errors without regard to serial position. Omission errors were rare, since Ss seem to have learned that the probe was in the array on $80 \%$ of the trials and so guessed a location when in doubt. Increased exposure time decreased both location errors $[F(3,36)=12.16, \quad p<.001]$ and commission errors $[F(3,36)=12.72$, $\mathrm{p}<.001]$. The decreased accuracy with search was also shown in both location $[F(1,36)=33.05, p<.001]$ and commission $[F(1,36)=5.94$, $\mathrm{p}<.05]$. The interaction between exposure time and search was not significant for either error type $[F(3,36)=0.27$ and 2.37 , respectively ].

Figure 2 shows the effect of the target item on recall of the probed positions in the array. Enhancement of recall due to search was largely specific to the target item. The targets were recalled with practically perfect accuracy for exposures of 1 sec or more. Nevertheless, for exposures of $4 \mathrm{sec}$, the Ss improved most in the recall of probed items at the ends of the array away from the target.

\section{DISCUSSION}

The target of a search task served as a high-priority event and reduced effective presentation time of other items in the array. The search task reduced probed recall to a level slightly less than what was obtained at half the total exposure time regardless of the location or even the presence of the target. The lack of any significant interactions between search conditions and exposure time indicates that search and encoding were independent processes. Apparently, the Ss used some sort of time-sharing process with little overlap between the time used to search and the time used to store for recall.

When a target item was discovered, it was not used as an anchor point to aid recall, although the item itself was recalled in location better than any other item in the array. The Ss apparently located the target item by position rather than by adjacent items. For the recall requirements of this experiment, the Ss generally seemed to use the ends of the array, especially with longer exposure times. Thus, 
when concrete, perceptual factors such as the ends of an array can be separated from more abstract, cognitive factors such as primacy in memory, the perceptual factors seem to be more important for the selection of anchor points for recall (Harcum, Pschirrer, \& Coppage, 1968; Reitman, 1970 , p. 121).

REFERENCES

FEIGENBAUM. E. A.. \& SIMON. H. A. A theory of the serial position effect. British Journal of Psychology. 1962, 53. 307-320.

HARCUM. E. R. Parallel functions of serial learning and tachistoscopic pattern perception. Psychological Review, 1967. 74. 51-62.

HARCUM. E. R., PSCHIRRER. M. E., \& COPPAGE, E. W. Determinants of primacy for items in continuous serial learning. Psychological Reports, 1968. 22. 965-975.

REITMAN. J. S. Computer simulation of an information processing model of short-term memory. In D. A. Norman (Ed.), Hodels of human memory. New
York: Academic Press, 1970. Pp. 117-148.

SCHULZ. L. S. Effects of high-priority events on recall and recognition of other events. Journal of Verbal Learning \& Verbal Behavior, 1971, 10, 322-330.

TULVING, $E$. Retrograde amnesia in free recall. Science, 1969, 164, 88-90.

von RESTORFF. H. Über die Wirkung von Bereichsbildungen im Spurenfeld. Psychologische Forschung, 1933, 18 . 299-342.

WALLACE, W. P. Review of the historical, empirical, and theoretical status of the von Restorff phenomenon. Psychological Bulletin, 1965, 63, 410-424. 